\title{
ist \\ Modelo causal dos primórdios da ciência do magnetismo
}

\author{
Osvaldo Pessoa Júnior
}

\begin{abstract}
电
RESUMO

Este artigo apresenta uma breve história do nascimento da ciência do magnetismo, que ocorreu em três continentes distintos de maneira independente. Aplica-se a metodologia dos modelos causais em história da ciência para representar esses caminhos independentes, onde aparece a noção de "gargalo de desenvolvimento". Ênfase é dada para a definição de "avanços generalizados”, que reúnem diferentes espécies de avanços e simplificam os diagramas causais. O relato histórico enfoca os avanços na China e na Europa até 1600 .
\end{abstract}

Palavras-chave: Pedra-imã. Bússola. História do magnetismo. Modelos causais.

Gargalo de desenvolvimento. Avanços generalizados.

\section{INTRODUÇÃO}

A abordagem da história da ciência que se baseia em "modelos causais" busca descrever a história da ciência a partir de unidades de conhecimento, chamadas "avanços", que se interligam mediante relações causais, cuja "força causal" varia com o tempo (cf. Pessoa Júnior, 2006; no prelo). O presente texto utiliza esse enfoque para tratar dos primórdios da ciência e tecnologia do magnetismo.

Modelos causais permitem também exprimir "histórias contrafactuais", ou seja, histórias possíveis que não ocorreram (cf. Pessoa Júnior, 2000). No presente estudo, não se pretende especular sobre histórias contrafactuais, mas sim comparar três histórias factuais possíveis, que ocorreram na Antiguidade de maneira paralela e independente, na Europa, na China e na América Central.

A metodologia de investigação baseia-se em um exame da literatura secundária sobre a história e a arqueologia dos primórdios das técnicas e conhecimentos sobre o magnetismo. Selecionam-se os avanços mais importantes, que incluem descobertas, explicações e instrumentos fabricados. Para cada avanço, estabelecem-se quais foram os avanços anteriores que condicionaram ou "causaram" seu surgimento. Propõe-se um modelo causal único que descreva as histórias nas diferentes culturas. 


\section{A PEDRA-IMÃ}

O primeiro passo para o desenvolvimento do campo do magnetismo foi a descoberta da pedra-imã e exploração do chamado efeito pedra-imã, ou seja, a atração que minérios de pedra-imã exercem sobre pedaços de ferro e de alguns minérios de ferro. O efeito é conhecido desde os primórdios das civilizações meso-americanas, egípcia, egéia e chinesa. Autores gregos citam os estudos de Tales de Mileto (c. 570 a.C.), que também conhecia o efeito atrativo (eletrostático) que o âmbar esfregado exerce sobre pequenos pedaços de quaisquer materiais.

Tales associava o efeito da pedra-imã à ação da alma, enquanto Empédocles explicava o efeito a partir do princípio do amor (que junto com o ódio regeriam o cosmo). Explicações semelhantes foram oferecidas posteriormente, em torno de 200 d.C., por Alexandre de Afrodisias e por Galeno, para quem o ferro obteria nutrição da pedraimã, havendo pois um tipo de força vital que atrairia o ferro ao imã.

Demócrito de Abdera (c. 4,20 a.G.) escreveu um tratado intitulado Sobre o magneto, que não chegou até nós, mas foi comentado por Alexandre de Afrodisias. A explicação atomista para o magnetismo aparece também em 60 a.C. no famoso poema de Lucrécio, Da natureza (cf. 1980 [c. 6o a.C], livro vi, linhas 998-1088). Para a atração de pedaços de ferro por uma pedra-imã, Lucrécio sugeriu um mecanismo envolvendo a emanação de minúsculas "sementes" do imã, que criariam um vácuo na face anterior da amostra de ferro, resultando em uma pressão que atrairia o ferro para o imã; o que explicaria também por que o ferro é repelido pelo imã após o contato (fenômeno da repulsão magnética). Lucrécio (livro vi, linhas 907-917) mencionou a suspensão de uma série de anéis de ferro por uma pedra-imã, exemplificando o fenômeno da indução magnética no ferro, ou seja, sua capacidade de ficar temporariamente imantado após contato com um imã. (Sobre o período greco-romano, cf. Mitchell, 1946; Needham, 1962, p. 231-7, 245-9; Daujat, 1945).

\footnotetext{
1 "Pedra-imã" é a tradução do inglês lodestone, cujo significado etimológico seria leading stone ou "pedra condutora", em referência à bússola magnética. O termo designa qualquer amostra natural de minério que tenha magnetização permanente. As pedras-imãs mais fortes são obtidas naturalmente a partir da magnetita $\left(\mathrm{Fe}_{3} \mathrm{O}_{4}\right)$, mas também estão associadas a outros minérios, incluindo os produtos de oxidação da magnetita, a maghemita e a hematita $\left(\mathrm{Fe}_{2} \mathrm{O}_{3}\right)$. Sabe-se hoje que a magnetização da hematita é devida a domínios de maghemita. Assim como o ferro, toda amostra de magnetita é atraída por um imã permanente (sendo assim identificável com uma bússola), mas apenas uma pequena parte da magnetita terrestre tem magnetização permanente (ou seja, é pedra-imã). Uma das hipóteses para a origem das pedras-imã é que sua magnetização permanente é causada pela queda de raios em veios superficiais dos citados minérios, o que explica porque pedras-imã não são encontradas em minas profundas (cf. Wasilewski \& Kletetschka, 1999).
} 
Relatos sobre o efeito da pedra-imã na China remontam pelo menos ao ano 220 a.C., com Pu Wei; cem anos depois, já se tinha observado a repulsão entre ferro e imã (cf. Needham, 1962, p. 232, 237). Assim, por volta dessa época, o conhecimento sobre o magnetismo na China estava no mesmo estágio que na Europa, com a diferença talvez que, na Grécia, em Alexandria e em Roma, havia um debate mais intenso a respeito de como explicar o fenômeno, ao passo que na China dominava a explicação baseada no movimento do chhi (semelhante ao pneuma dos estóicos) entre a "pedra do amor" e o ferro.

O efeito da pedra-imã também era conhecido na América Central, como é demonstrado por esculturas em pedra magnetizada encontradas na região de Soconusco, na costa do Pacífico no sul do México e oeste da Guatemala. Dentre tais esculturas, destacam-se a cabeça de uma tartaruga em Izapa, com volume em torno de $1 \mathrm{~m}^{3}$, cujo focinho localiza-se exatamente no polo norte do magneto. Outra série de esculturas, conhecida como "Fat boys", também indica o conhecimento dos polos magnéticos da pedra-imã esculpida. Tais esculturas têm sido datadas de 1200 a 500 a.G., e atribuídas a povos do período formativo da cultura maia. É possível que a orientação magnética das pedras ficasse evidente a partir da atração exercida sobre a limalha da pedra-imã esculpida (cf. Malmström, 1997, cap. 3).

\section{A PROPRIEDADE DIRETIVA DA PEDRA-IMÃ}

A evolução de um campo científico pode ser comparada ao desenvolvimento de um organismo dentro de um ambiente particular. Típico de processos de desenvolvimento é a existência de um grande número de elementos em interação e a presença ocasional de gargalos: um novo estágio de desenvolvimento só pode surgir após alguns elementos terem atingido algum grau de amadurecimento.

A ciência do magnetismo, na Europa, não conseguiu ultrapassar o primeiro estágio descrito na seção anterior. O gargalo, que não foi transposto, foi o da descoberta da propriedade diretiva da pedra-imã, ou seja, sua capacidade de orientar-se em relação ao meridiano que liga o norte e o sul, como fazem as bússolas magnéticas. Essa propriedade só viria a ser conhecida na Europa no século xII, um milênio depois da existência de sua documentação na China. Um relato da propriedade diretiva da pedraimã foi dado por Liu An, em 120 a.C., que descreveu uma agulha de pedra-imã flutuando na água e, em 83 d.C., Wang Chhung descreveu uma rudimentar bússola magnética usada para adivinhação (cf. Needham, 1962, p. 261-2). O que se seguiu após esse avanço, ao longo dos séculos seguintes, foi um segundo estágio de desenvolvimento da ciência do magnetismo, que culminou com a bússola náutica. 

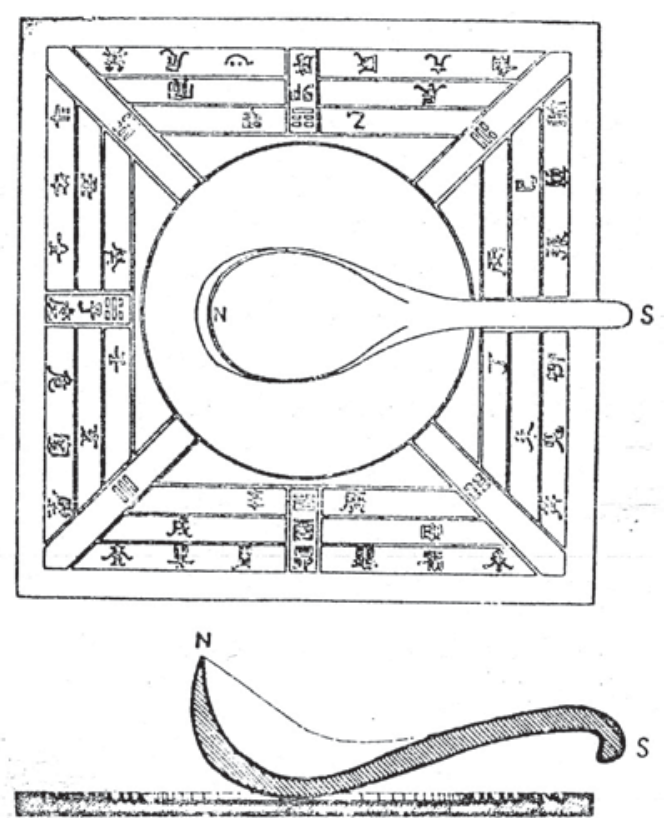

Figura 1. Reconstrução do tabuleiro de adivinhação, com a colher de pedra-imã girante ao centro. Reconstrução feita por Wang Chen-To (Needham, 1962 , p. 266).

Por que a propriedade diretiva do imã foi descoberta e transmitida na China, mas não na Europa? Uma das causas foi a existência, na China, de práticas de adivinhação que forneceram um ambiente propício para que a descoberta ocorresse. O Tao Te Ching de Lao Tzu (3oo a.C.) já mencionava o uso de um tabuleiro mágico, chamado shih, que consistia de duas partes (ver fig. 1). Em baixo, um tabuleiro quadrado simbolizava a Terra, sendo dividido radialmente em diferentes regiões, com marcações que incluíam os oito kua do I Ching. Em cima, um prato redondo representando o Céu estava livre para girar, contendo os 24. pontos cardeais e uma figura da constelação do Grande Urso. Uma variante dessa técnica envolvia pequenos modelos (como peças de xadrez) que eram atirados no tabuleiro. Uma dessas peças, feita de pedra-imã e tendo a forma do Grande Urso (parecendo uma colher de sopa), tendia sempre a apontar (com seu cabo) para o sul, quando girada. É este artefato de magia que constituiu a primeira bússola chinesa, descrita por Wang Chhung em 83 d.C. ${ }^{2}$

Tais técnicas de magia foram posteriormente incorporadas na arte taoista de "geomancia" (Feng shui), que buscava adaptar moradias e paisagens às correntes de sopro cósmico (chhi). Em torno do ano 1000, a escola de Fukien de geomancia floresceu perto do mar, dando destaque especial para o uso da bússola, que acabou sendo levada para a navegação (cf. Needham, 1962, p. 239-44, 261-9, 281-3, 314-3o). Vemos, assim, um exemplo de como, na Antiguidade, a ciência estava intimamente entrelaçada com outros aspectos da cultura.

Há boa evidência de que a propriedade diretiva da pedra-imã era conhecida anteriormente na América Central. Tal afirmação baseia-se principalmente na descoberta de uma pequena barra cuidadosamente polida de hematita magnética em San Lorenzo, no atual estado de Veracruz, ao sul do México, datada do período formativo da cultura olmeca, entre 14,00 e 1000 a.G. A peça é retangular, possuindo um sulco ao longo de sua extensão maior, e foi encontrada quebrada, com comprimento de $3,4 \mathrm{~cm}$ 2 Há um exemplar dessa colher de pedra-imã na Academia Brasileira de Ciências, no Rio de Janeiro. 


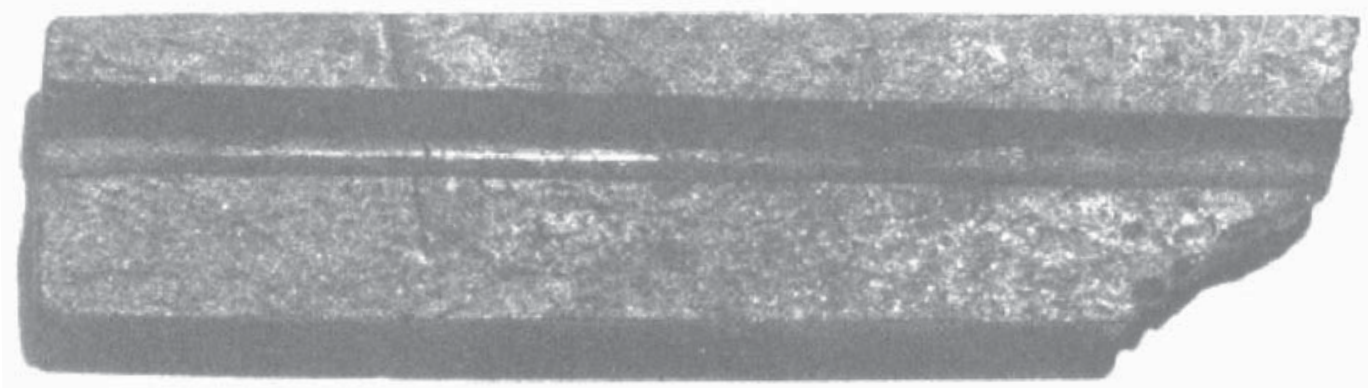

Figura 2. Fotografia do paralepípedo quebrado de pedra-imã olmeca, medindo $3,4 \mathrm{~cm}$, conhecido como artefato M-160. Nota-se o sulco quase paralelo à borda. Estima-se que a peça original teria o dobro do comprimento (Carlson, 1975, p. 757 ).

(Fig. 2). É possível que os olmecas colocassem a peça flutuando em mercúrio, pois sabese que povos meso-americanos extraíam mercúrio líquido a partir do aquecimento de cinábrio (HgS). Dessa maneira, a peça poderia ser usada como uma bússola (cf. Carlson, 1975). Outra evidência do conhecimento da propriedade diretiva pelos povos mesoamericanos é o alinhamento sistemático de suas edificações em uma direção apontando para em torno de $10^{\circ}$ para leste do sentido norte geográfico. Isso poderia ser explicado levando-se em consideração que o norte magnético varia com o passar do tempo (Klokoèník et al., 2007).

\section{Modelo GaUsal do início da GiÊnGia do MAGNetismo}

As informações históricas precedentes podem ser resumidas no modelo causal apresentado na figura 3. O ponto de partida é o avanço “efeito da pedra-imã”, que surgiu independentemente na América Central, na Europa e na China, em regiões onde obviamente havia depósitos de pedra-imã. A disponibilidade de pedra-imã (e também, certamente, a existência de seres vivos inteligentes) pode ser considerada uma causa necessária para o surgimento desse avanço, não sendo a disponibilidade em si mesma um avanço ou forma de conhecimento (mas sim um fato do mundo). Essa causa factual é representada na figura 3 como uma elipse.

O avanço "propriedade diretiva do imã" surgiu na América Central e na China e, nesta última, há evidências de que o caminho seguido para a descoberta envolveu a elaboração de uma agulha de pedra-imã colocada para flutuar em água (um pouco de graxa garantiria que a agulha não afundasse). Tal avanço "agulha flutuante de pedraimã" teria sido uma consequência da conjunção do efeito da pedra-imã e da manifestação cultural de "adivinhação com agulha flutuante em água”. 


$-200-100+0$

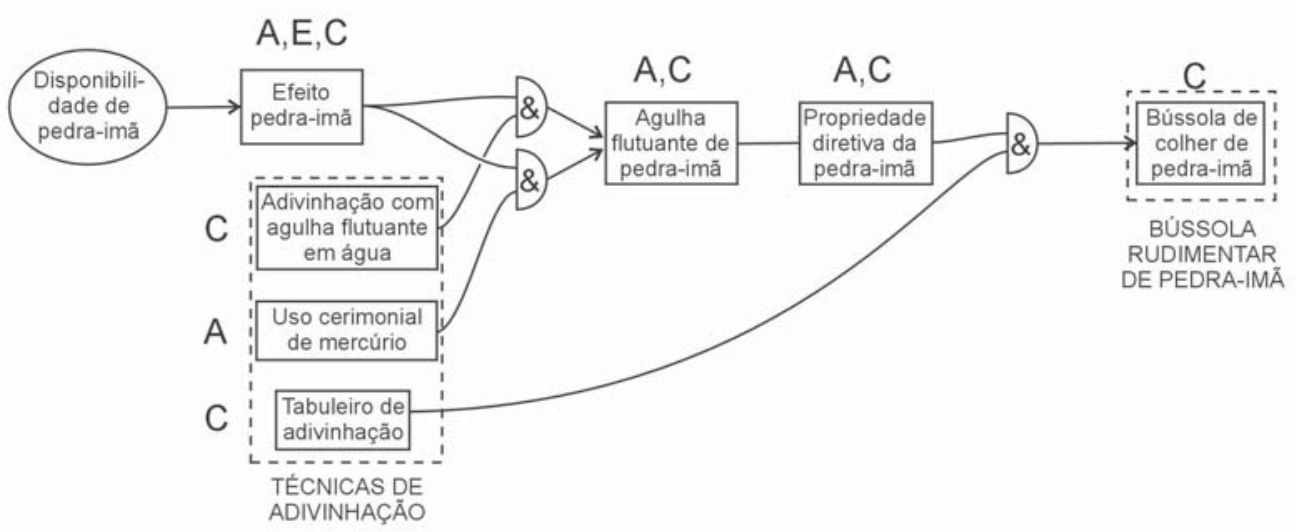

Figura 3. Modelo causal do desenvolvimento da bússola rudimentar. $O$ efeito da pedra-imã era conhecido na América Central (A), Europa (E) e China (C), mas apenas em A e C descobriu-se a propriedade diretiva da pedra-imã. A causa disso teria sido a forte presença de técnicas de adivinhação nessas duas regiões. A linha do tempo, acima, indica as datas dos avanços na China. $O$ signo " $\&$ " designa a conjunção de causas, e duas setas apontando para um mesmo avanço indicam a disjunção de causas.

No caso da América Central, Carlson sugeriu que a descoberta da propriedade diretiva da pedra-imã teria seguido um passo intermediário análogo ao do caso chinês, envolvendo o "uso cerimonial do mercúrio". Na figura 3, esses dois caminhos estão representados por meio de conjunções "\&". No entanto, está claro que ambos os avanços ("adivinhação..." e "uso cerimonial...") podem ser reunidos em um avanço mais geral, que seria um "gênero" das duas espécies de avanços mencionadas, e que podemos chamar de "técnicas de adivinhação". Tal classe de avanços reuniria também um terceiro avanço, "tabuleiro de adivinhação", que Needham considerou importante para a construção da primeira bússola rudimentar, a "bússola de colher de pedra-imã", mencionada em 83 d.C.

Eis, então, um primeiro exemplo de uma reunião de avanços sob um gênero, fornecendo um avanço generalizado que simplifica o modelo causal, indicando o que haveria de comum nos diferentes avanços que causam (em conjunção com o efeito da pedra-imã) o surgimento do avanço "propriedade diretiva da pedra-imã” em diferentes histórias possíveis. Examinaremos outro exemplo de avanço generalizado na seção 5 .

Segundo o presente modelo, a explicação de por que a propriedade diretiva da pedra-imã não foi descoberta na Europa seria que não houve, na Antiguidade Greco-Romana, uma incorporação da pedra-imã em rituais de adivinhação. Tal explicação é elaborada em um modelo causal com probabilidades numéricas em Pessoa Júnior (2006). 
No entanto, a ilha grega de Samotrácia, no norte do Mar Egeu, era um importante centro de culto secreto aos deuses ctônicos (da terra e do inferno), especialmente os "cabiros", que eram deuses do fogo e da metalurgia. Na ilha, havia minério de ferro, incluindo pedra-imã, e há relatos de anéis de ferro banhados a ouro que poderiam ser magnetizados e atraírem-se. Encontrou-se na ilha um tabuleiro de adivinhação dividido em 16 direções, conhecido como "disco de Praga", e que poderia ter sido usado por um adivinho, com uma pedra-imã que atrairia os anéis (cf. Aczel, 2002, p. 44-6, 95). A passagem em que Lucrécio (livro vi, linha 1044) menciona a repulsão magnética de pedaços de ferro faz referência a Samotrácia. O modelo causal da figura 3 sugere que a presença simultânea do efeito pedra-imã e de técnicas de adivinhação leva, com boa probabilidade, à descoberta da propriedade diretiva da pedra-imã. Assim, seria de se esperar que tal propriedade pudesse ter sido conhecida na antiga Samotrácia, mas que esse conhecimento, se de fato obtido, teria permanecido secreto e posteriormente perdido.

\section{O DESENVOLVIMENTO DA BÚSSOLA DE PREGISÃO}

As artes divinatórias chinesas tiveram um papel importante também na preservação e transmissão do conhecimento relativo à propriedade diretiva da pedra-imã e na exploração desse efeito. Há evidências de que, em torno de 4,00 d.G., os chineses já imantavam agulhas de ferro (cf. Needham, 1962, p. 277-8), esfregando-as em uma pedraimã. Isso levou ao desenvolvimento da primeira forma precisa de bússola. Em 983, há uma descrição de uma agulha magnetizada suspensa por um fio de seda novo, grudada a ele por um pedaço de cera do tamanho de uma semente de mostarda. Em um local sem vento, diz o relato, a agulha sempre aponta para o sul. Esta é a descrição mais antiga de uma bússola de precisão, que não sofre os efeitos do atrito que limitavam a precisão da colher de pedra-imã dos adivinhos (cf. Needham, 1962, p. 274-8).

O grande astrônomo chinês Shen Kua, em 1088, mencionou não só a bússola suspensa por um fio, mas também a bússola flutuante, que consistia em uma agulha imantada, presa a um pedaço de palha ou junco, que boiava na água. Uma versão que se difundiria consistia de uma folha de ferro imantado na forma de um peixe, que flutuava na água (ver fig. 4). Shen Kua não fez menção do uso náutico da bússola, mas há um relato de 1117 que o faz inequivocamente, referindo-se a um período posterior a 1086 no porto de Cantão, no sul da China (cf. Needham, 1962, p. 279).

Havia também uma bússola feita de pedra-imã, inserida em uma tartaruga de madeira com um cabo indicador de direção. A tartaruga era sustentada e girava em um pivô seco, feito de um fino eixo vertical de bambu (ver fig. 5). Por fim, é interessante 


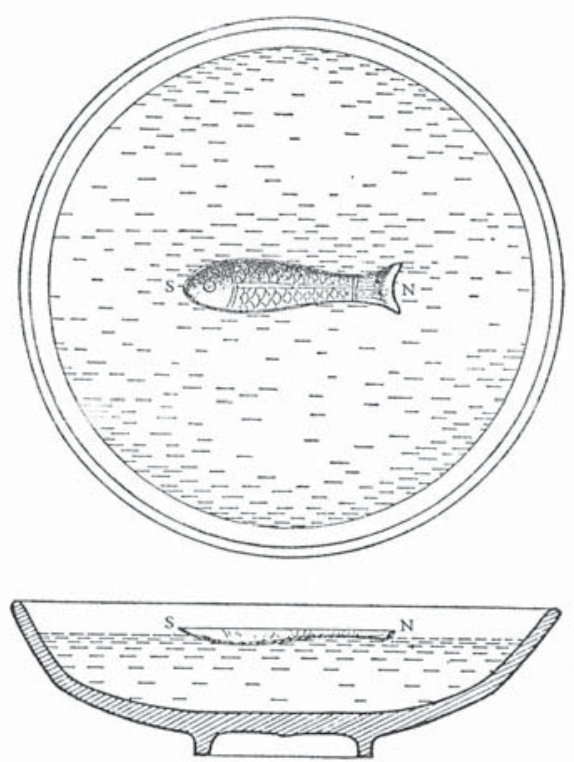

Figura 4. Folha flutuante de ferro magnetizado em forma de peixe, descrito no ano de 1044. Reconstrução desta e da figura seguinte foram feitas por Wang Chen-To (Needham, 1962, p. 253).

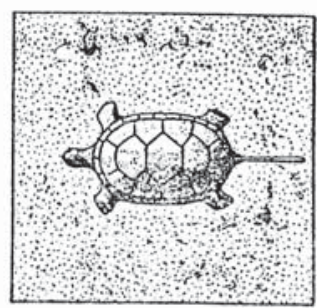

停藏

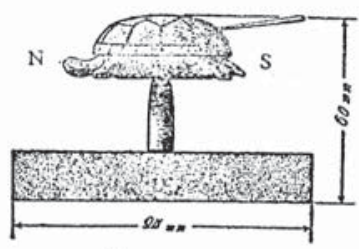

財

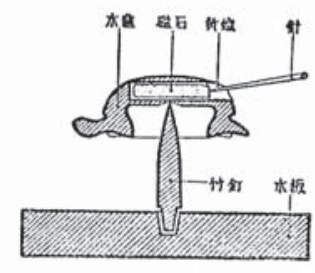

败 部面

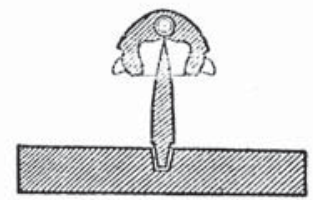

橫 剖 面
Figura 5. Bússola de pivô seco, formada por pedra-imã e agulha, presas a uma madeira esculpida na forma de uma tartaruga, descrita em $115^{\circ}$ (Needham, 1962, p. 257).

sublinhar que os chineses já haviam descoberto o fenômeno da "termo-remanência", que consiste em magnetizar uma agulha de ferro aquecendo-a a uma alta temperatura (acima de $700^{\circ} \mathrm{C}$ ) e deixando-a resfriar imóvel (de preferência alinhada com o meridiano terrestre). Assim, bússolas podiam ser fabricadas sem a presença de pedra-imã.

O período de desenvolvimento dessas diferentes formas de bússola de precisão e seu uso na navegação é estimado por Needham (1962, p. 281) como tendo ocorrido na China entre 850 e 1050 .

\section{O AVANÇO GENERALIZADO DA “BÚSSOLA DE PREGISÃo”}

A figura 6 representa as informações sobre o desenvolvimento da bússola de precisão em um modelo causal. Conforme vimos, a agulha magnetizada por contato com uma pedra-imã surgiu em torno de 400 d.C., e a partir de aproximadamente 850 apareceram diferentes espécies de bússolas de precisão feitas de tais agulhas. Bússolas com agulhas ou placas magnetizadas por termo-remanência também apareceram por essa 
época, assim como bússolas com grandes pedaços de pedra-imã e um ponteiro. Cada um desses avanços individuais pode ser agrupado como uma espécie do avanço generalizado "bússola de precisão".

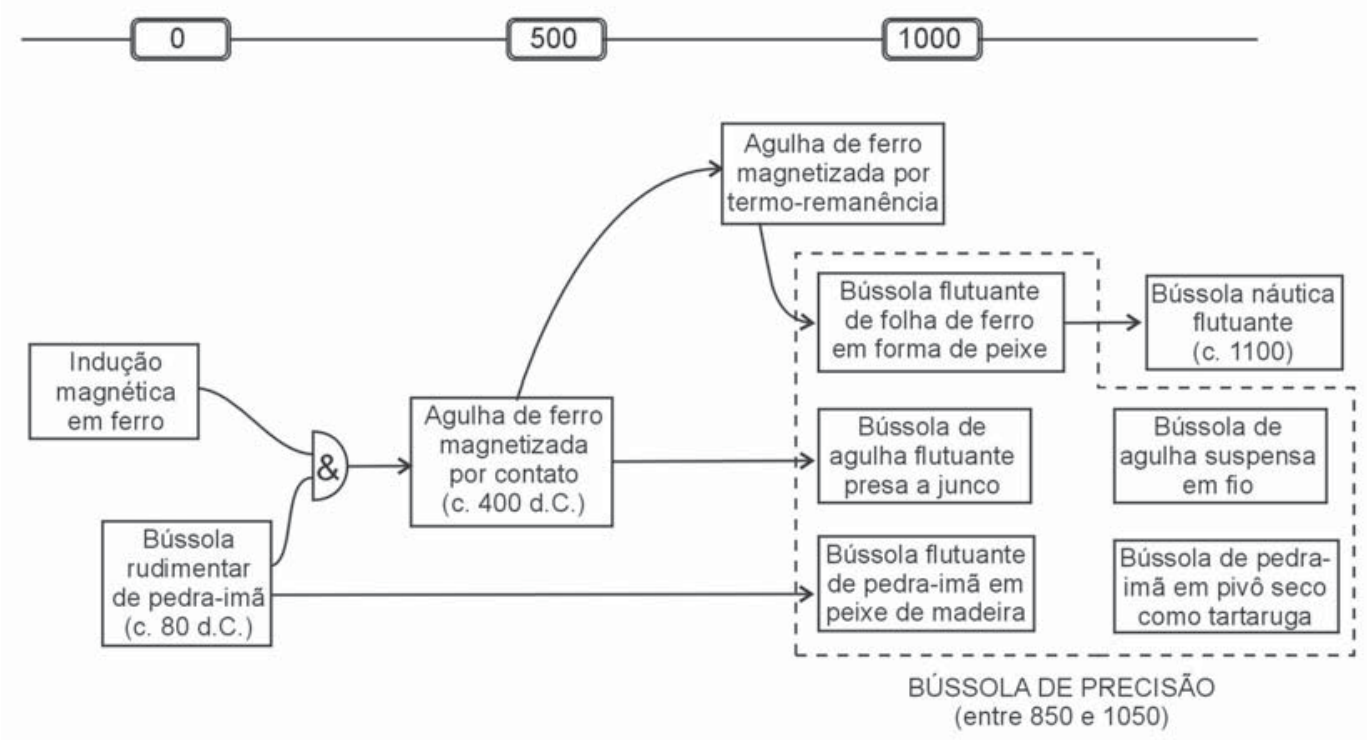

Figura 6. Modelo causal do surgimento, na China, da bússola de precisão, indicada como avanço generalizado por meio de linhas tracejadas.

A adaptação dessas bússolas para uso náutico aconteceu em torno de 1100, na China. A primeira forma relatada foi uma folha de ferro magnetizada em formato de peixe (ver fig. 4), mas qualquer uma das espécies de bússola poderia ter sido adaptada para uso marítimo. Assim, pode-se tomar o avanço generalizado "bússola de precisão" como a causa do avanço generalizado "bússola náutica”, e tal relação causal manter-se-ia válida na maioria das histórias contrafactuais da ciência do magnetismo. O que variaria de história possível para história possível seria a espécie particular de bússola adaptada.

O avanço generalizado indica o que haveria de "essencial" (para utilizar uma terminologia aristotélica) nas diferentes espécies de avanços (como as cinco indicadas entre linhas tracejadas na figura 6). No avanço generalizado, abstraem-se as diferenças "acidentais" que ocorrem nas diversas histórias possíveis do episódio. Pode-se afirmar que o avanço generalizado "bússola de precisão" estaria presente na grande maioria das histórias possíveis da ciência do magnetismo, mesmo que dentre elas sur- 
gissem espécies diferentes de bússola. Assim, a bússola de precisão pode ser considerada um gargalo para a descoberta de outras propriedades do magnetismo (que veremos na seção 8).

Pode-se também dizer que o avanço generalizado "bússola de precisão" é o menor gênero (ou "espécie ínfima") que captura a classe de avanços pertinentes a esta etapa da ciência do magnetismo. 0 exemplo de avanço generalizado dado na seção 3 , "técnicas de adivinhação", não é uma espécie ínfima, pois há diversas técnicas de adivinhação que não poderiam fazer uso da pedra-imã.

\section{O MISTÉRIO DA TRANSMISSÃO DA BÚSSOLA PARA A EUROPA}

Existe um mistério quanto à origem da bússola no Ocidente. A primeira descrição confirmada foi a de Alexander Neckham, monge em Saint Albans (Inglaterra), escrita pouco depois de 1187, após passar vários anos em Paris e ter viajado para a Itália (cf. Aczel, 2002, p. 31). Ele descreveu o uso náutico de uma bússola flutuante e de uma bússola com pivô seco (cf. Mitchell, 1932, p. 125). Em torno de 1206, Guyot de Provins, que havia viajado para Bizâncio e para a Palestina, e vivia em Cluny, descreveu o uso da bússola náutica flutuante em um poema (transcrito em Needham, 1962, p. 246-7). O cardeal Jacques de Vitry lançou em 1218 uma descrição da Palestina (onda fora bispo na cidade de Acre) em que diz ter visto a bússola náutica em uso em 1204.

Uma primeira hipótese seria de que a bússola teria sido desenvolvida na Europa de forma independente da China, como sugerem alguns autores mais antigos, como Mitchell (1932, p. 130). No entanto, parece improvável que a propriedade diretiva da bússola tivesse sido descoberta e adaptada ao uso náutico antes que qualquer relato da descoberta tivesse sido feito - lembremos que na China essa transição demorou mil anos. Há uma lenda de que o inventor da bússola náutica teria sido um certo Flavio Gioia, da cidade costeira italiana de Amalfi, no reino de Nápoles, em 1301. A desconstrução dessa lenda foi feita pelo padre Timoteo Bertelli, nas comemorações do hexacentenário desse evento, em 1901 (cf. Mitchell, 1932, p. 127-8; Aczel, 2002, p. 55-63). Pode-se, porém, aceitar a hipótese de que marinheiros da região de Amalfi tenham introduzido o "cartão de bússola", um fino cartão preso à agulha, contendo o desenho da rosa dos ventos ou qualquer indicação dos pontos cardeais. A montagem da bússola era feita em pivô seco e a peça era enclausurada em uma caixa circular. Tal dispositivo disseminou-se na Europa no século xiv e chegou a China somente dois séculos depois (cf. Needham, 1962, p. 288-9).

Uma segunda hipótese, a mais plausível, é de que a bússola tenha sido trazida por mar (ao ser usada como bússola náutica) por marinheiros muçulmanos. Lembre- 
mos que relatos sobre a bússola náutica em Cantão são de em torno de 1086, época em que mercadores árabes circulavam pelo porto. Após o envio da primeira missão diplomática em $65^{1}$ e do ataque a Cantão em $75^{8}$, os árabes estabeleceram colônias no século Ix em Cantão e Hangchow. A navegação árabe manteve sua supremacia no Índico até o século XII. Nos anos 1081 e 1091, missões diplomáticas foram enviadas por mar pelos turcos seljúcidas (de Bagdá) para a China (cf. Needham, 1954, p. 179-80, 214-6). Em torno dessa época, uma ou mais bússolas poderiam ter sido trazidas por mar, talvez para Alexandria, e transmitidas para mercadores de Amalfi, que tinham comércio ativo com os muçulmanos.

Acontece, porém, que não se conhece nenhum relato sobre a bússola no mundo islâmico antes de 1232, quando Muhammad al-Awfi escreveu uma coleção de histórias persas, em que menciona ter visto uma bússola flutuante feita de uma folha de ferro na forma de um peixe (como a usada pelos chineses, ver figura 4), provavelmente na foz do rio Indus em torno de 1220, então sob domínio árabe (cf. Mitchell, 1932, p. 119; Needham, 1962, p. 254). Depois, Bailak de Kibdjadi, em 1282, descreveu uma bússola flutuante que viu em uso em 1242, em uma viagem mediterrânea de Trípoli (na Palestina) para Alexandria. Devido à ausência de relatos, há uma opinião disseminada entre os historiadores da questão de que não houve transmissão da bússola náutica por navios árabes.

A terceira hipótese é que teria havido transmissão terrestre da bússola, através do continente asiático, na chamada "rota da seda". Gilbert (1958 [1600], I, §1) menciona que a bússola foi trazida por terra da China por Marco Polo, mas a data de 1260 é posterior ao do texto de Neckham, de 1187. A rota da seda tivera importância na época romana e também no século xiII (quando o Ocidente já produzia sua própria seda). Porém, após a derrota dos chineses para os muçulmanos no Rio Talas, em 751, o comércio pela rota terminou (cf. Needham, 1954, p. 181-90). Mesmo assim, Needham (1962, p. 332) defende a hipótese da transmissão terrestre, sugerindo um papel central para o reino de Catai (ou canato de Kara-Khitan, situado entre a China e o Sultanato dos Turcos Seljúcidas), que em 1141 derrotou os turcos seljúcidas em Samarcanda.

Quer a bússola tenha vindo por terra ou por mar, é plausível supor que os europeus a tenham obtido durante ou após a $1^{\text {a }}$ Cruzada, que se iniciou em 1096. As tropas cristãs passaram por Constantinopla e dirigiram-se para a Palestina, onde conquistaram Edessa, Antióquia, Jerusalém e Trípoli (esta só em 1109). Um exame desse período sugere a hipótese de que as Cruzadas e a presença franca, normanda e italiana na Palestina (e também no Império Bizantino) tenha feito com que alguém travasse contato com uma bússola vinda da China. Essa região, conhecida como Levante, foi dominada pelos cristãos durante a maior parte do século XII, e houve um contato intenso com a cultura muçulmana. O Mediterrâneo passou a ser dominado pelos normandos, 
que governavam a Sicília, pelos genoveses e pelos venezianos, que venceram os fatimidas egípcios na batalha naval de Ascalon em 1123. Havia bastante contato com comerciantes muçulmanos, especialmente em Alexandria. Parece bastante plausível que uma bússola flutuante ou de pivô seco tenha sido adquirida pelos cristãos normandos, franceses ou italianos. Ao retornarem de navio, o uso da bússola para navegação teria aplicação imediata. O período 1160-80 parece uma boa estimativa para a introdução da bússola no Ocidente, nas décadas anteriores à sua primeira descrição extante.

\section{Petrus Peregrinus}

O mais importante tratado medieval sobre o magnetismo foi escrito por Pierre de Maricourt, mais conhecido como Petrus Peregrinus. Ele provavelmente era um engenheiro militar que participava do cerco de Lucera (na Itália), ao lado do exército de Charles de Anjou, rei normando da Sicília, que lutava para expulsar os germânicos da península itálica. Nesse episódio, ocorrido em 1269, Petrus redigiu suas investigações experimentais sobre a terrella, ou seja, uma esfera de pedra-imã. Colocando uma agulha imantada em diferentes pontos da superfície da terrella e desenhando a orientação da agulha na superfície da esfera, obteve linhas iguais aos meridianos terrestres, ou seja, grandes círculos que se cruzam em dois polos opostos. Outro método para localizar os polos da terrella consistia em encontrar os pontos nos quais a agulha imantada ficasse "em pé", perpendicularmente à superfície do globo de pedra-imã (cf. Peregrinus, 1943 [1269]).

Descreveu o experimento em que colocou a pedra-imã em um prato fundo, boiando na água, de tal forma que o polo "norte" da pedra se orientava para o polo norte celeste. Dividindo a pedra em duas partes ao longo de seu equador, cada uma terá um polo norte e um sul, e os polos diferentes se atraem. Peregrinus não conhecia a declinação magnética (ver seção 8), de tal forma que achava que um imã aponta exatamente para o polo norte celeste. Isso o levou à concepção de que cada parte da terrela era atraída por um ponto correspondente na esfera celeste, visão defendida também por Roger Bacon, em 1266.

Uma consequência desta concepção foi um experimento que Peregrinus sugere ter realizado, no qual uma terrella é presa nos polos e estes são alinhados aos polos terrestres. Ele escreve que observou uma rotação diurna da terrella com período de 24 horas, ou seja, cada ponto da terrella acompanharia o movimento de seu ponto correspondente na esfera celeste. Tal experimento parece ter sido repetido por Hartmann, mas tanto Gilbert quanto Galileu o rejeitaram. 


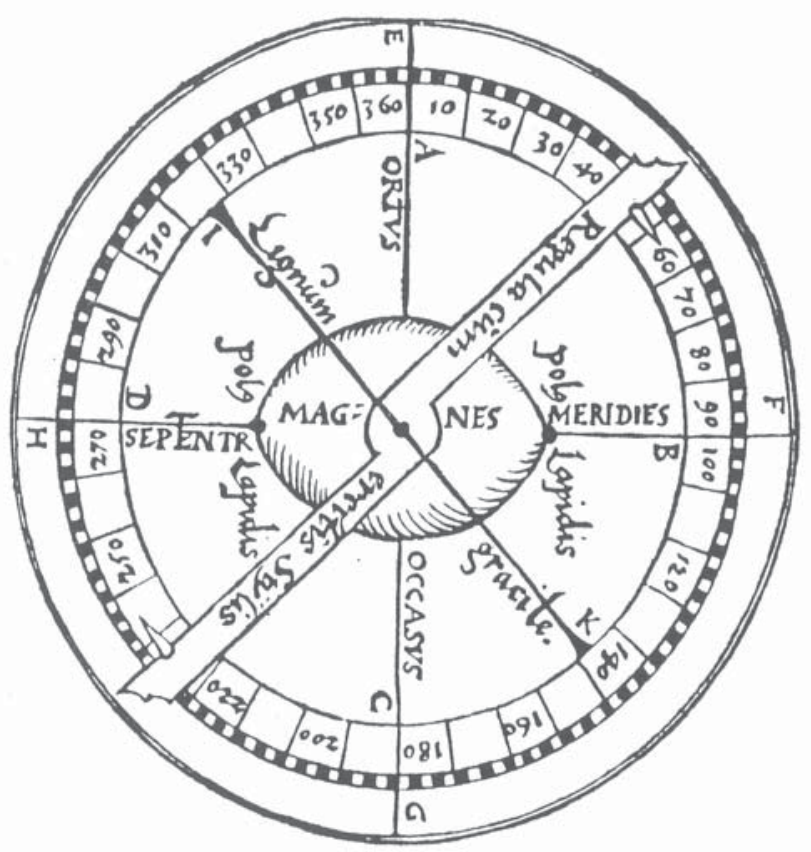

Figura ๆ. Bússola flutuante feita de pedra-imã, usada para encontrar o azimute de qualquer corpo celeste no horizonte, proposta por Peregrinus em 1269 (Harradon, 1943a, p. 14).

Peregrinus também sugeriu uma máquina de movimento perpétuo baseada no magnetismo, mas, certamente, tal máquina não funciona. Na segunda parte de seu trabalho, ele descreve com detalhes a construção de uma bússola flutuante feita de pedraimã (ver fig. 7) e de uma bússola de agulha de ferro com pivô seco, ambas providas de uma escala com divisões a cada dois graus (cf. Harradon, 1943a; Grant, 2007).

\section{Novas DEScobertas}

O desenvolvimento da bússola de precisão, feita de uma agulha de ferro que se magnetizava ao ser esfregada a uma pedra-imã (ou por termo-remanência), permitiu aos chineses descobrirem que a agulha não aponta exatamente para o norte (ou sul) celeste, mas sim que possui um certo desvio angular. Esse fenômeno é conhecido como declinação magnética. Sua descrição foi feita de maneira clara por Shen Kua (em 1088) (mencionado na seção 4) e pelo naturalista Khou Tsung-Shih (em 1116). Este último escreveu que a agulha aponta para o sul com um desvio de $15^{\circ}$ para leste (em relação ao sul). 
Antes deles, porém, os praticantes da adivinhação geomântica já tinham notado o desvio, como indica um poema escrito em 1030 (cf. Needham, 1962, p. 293-13).

Os europeus só viriam a descobrir a declinação em torno de 1450 , como mostram os relógios de sol portáteis fabricados em Nuremberg e Augsburg, por volta dessa época. Tais instrumentos, fabricados por astrônomos como Peuerbach e Regiomontanus, vinham com uma bússola, necessária para indicar a direção norte, que trazia uma marca (em torno de $10^{\circ}$ para leste, em relação ao norte) que indicava a declinação, corrigindo desta forma a leitura que estabelecia o meio-dia (cf. Mitchell, 1937, p. 24,67; Harradon, 1943b, p. 127-8). Navegantes como Cristóvão Colombo, em 1492, e Sebastian Cabot, em 1497, parecem ter conhecido a declinação, que aparece em mapas de ${ }_{1536}^{36}$, quando já se conhecia a variação da declinação entre a Europa e a América, e a existência de uma "linha agônica" (de declinação nula) em torno do meridiano dos Açores (cf. Mitchell, 1937, p. 248-71; Gilbert, $195^{8}$ [1600], I.1).

Vale notar que os chineses mencionaram a declinação magnética cerca de 180 anos depois do desenvolvimento da bússola de precisão (ocorrida a partir do ano 850), ao passo que na Europa foram necessários cerca de 270 anos, a partir de 1180 . Essa diferença talvez possa ser explicada pela importância da geomancia na China, enquanto que na navegação no Mediterrâneo a pequena declinação existente não tinha consequências práticas. Isso está representado no modelo causal da figura 8 .

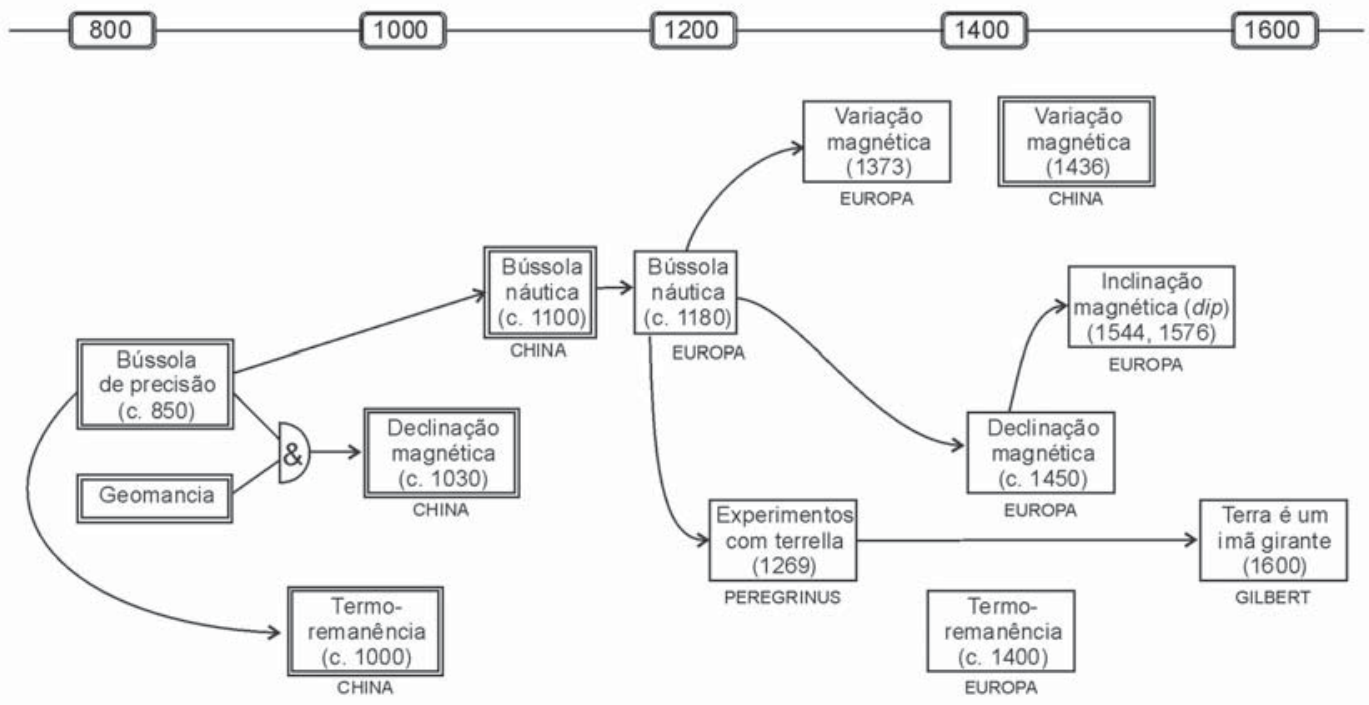

Figura 8. Modelo causal de avanços obtidos a partir da bússola de precisão. Alguns avanços são indicados duas vezes, com as datas de sua ocorrência na China (retângulo de linha dupla) e Europa (retângulo de linha simples). 
Outro fenômeno associado é a inclinação magnética (em inglês, dip), ou seja, o desvio da agulha para baixo do plano horizontal (em outras palavras, o componente vertical do campo magnético terrestre). Tal efeito não era conhecido na China, mas foi percebido pelo alemão Georgius Hartmann em 1544, que estimou uma inclinação de $9^{\circ}$, bem abaixo do valor real em Nuremberg, que seria em torno de $65^{\circ}$. Hartmann também descobriu que a declinação varia para diferentes localidades. $O$ erro de medição de Hartmann foi corrigido por Robert Norman, de Londres, que montou a agulha em um eixo horizontal (o que permitia que ela girasse livremente para baixo) e redescobriu (independentemente) o efeito em ${ }_{157} 6$ (cf. Mitchell, 1939).

Outro efeito atribuído à agulha magnética é chamado de variação magnética. Trata-se de variações no campo magnético devido à presença de rochas magnetizadas. Henrique de Hesse observou tal efeito em 1373 , na Noruega, e o chinês Fei Hsin o mencionou em 14.36. Quem explorou esse efeito com maior detalhe foi o navegante português João de Castro, que é considerado "o mais importante representante da oceanografia científica durante os últimos anos da era das descobertas" (Hellmann apud Harradon, 1944, p. 185-6). Castro anotou leituras constantes de sua bússola náutica entre Lisboa e Goa, em 1538. Na ilha de Chaul, na costa da Índia, percebeu que a agulha magnética era atraída por uma rocha. Castro também testou, com sucesso, o "instrumento da sombra" fabricado por Pedro Nunes, de Évora, que permitia a medição da altitude do Sol e a determinação da latitude a qualquer hora do dia.

\section{William Gilbert}

Tudo o que se conhecia a respeito do magnetismo até o Renascimento foi incorporado no livro De magnete (Do magneto), escrito em 1600 pelo inglês William Gilbert (15441603). Ele arrolou uma grande quantidade de observações a respeito de imãs e efeitos magnéticos, efetuando também experimentos. Distinguiu cinco fenômenos magnéti$\cos$ (Gilbert, 1958[1600], II, 1):

(1) a "coição" (atração, ou efeito pedra-imã);

(2) "direção" ou "verticidade" (propriedade diretiva);

(3) "variação" (que inclui o que chamamos hoje "declinação" e, também, a variação conforme o local);

(4) "declinação", "inclinação" ou "dip":

(5) a "revolução" da Terra, que seria explicada pela sua "energia magnética" (vi, 6). 
Descreveu também a termo-remanência, conhecida dos fundidores e forjadores de ferro, que resulta em magnetização permanente após o esfriamento do ferro fundido. Vimos, na seção 4, que essa propriedade era conhecida na China em torno do ano 1000. Na Europa, esse efeito não foi mencionado por Peregrinus, então podemos estimar sua descoberta em aproximadamente 14,00.

Gilbert seguiu Peregrinus, construindo uma terrella (esfera de pedra-imã), identificando seus polos, observando sua propriedade diretiva (em um barquinho na água) e descrevendo a atração e a repulsão entre polos de pedras-imã. De original, Gilbert introduziu a noção de que a Terra seria um grande imã, que gira em torno de seu eixo (como defendia Copérnico) com verticidade fixa (ao longo do eixo norte-sul do cosmo) devido à "forma primordial e energética" do seu magnetismo (I, 17). Uma terrella aponta para o polo terrestre da mesma maneira que uma pequena agulha imantada é orientada pela terrella. A declinação

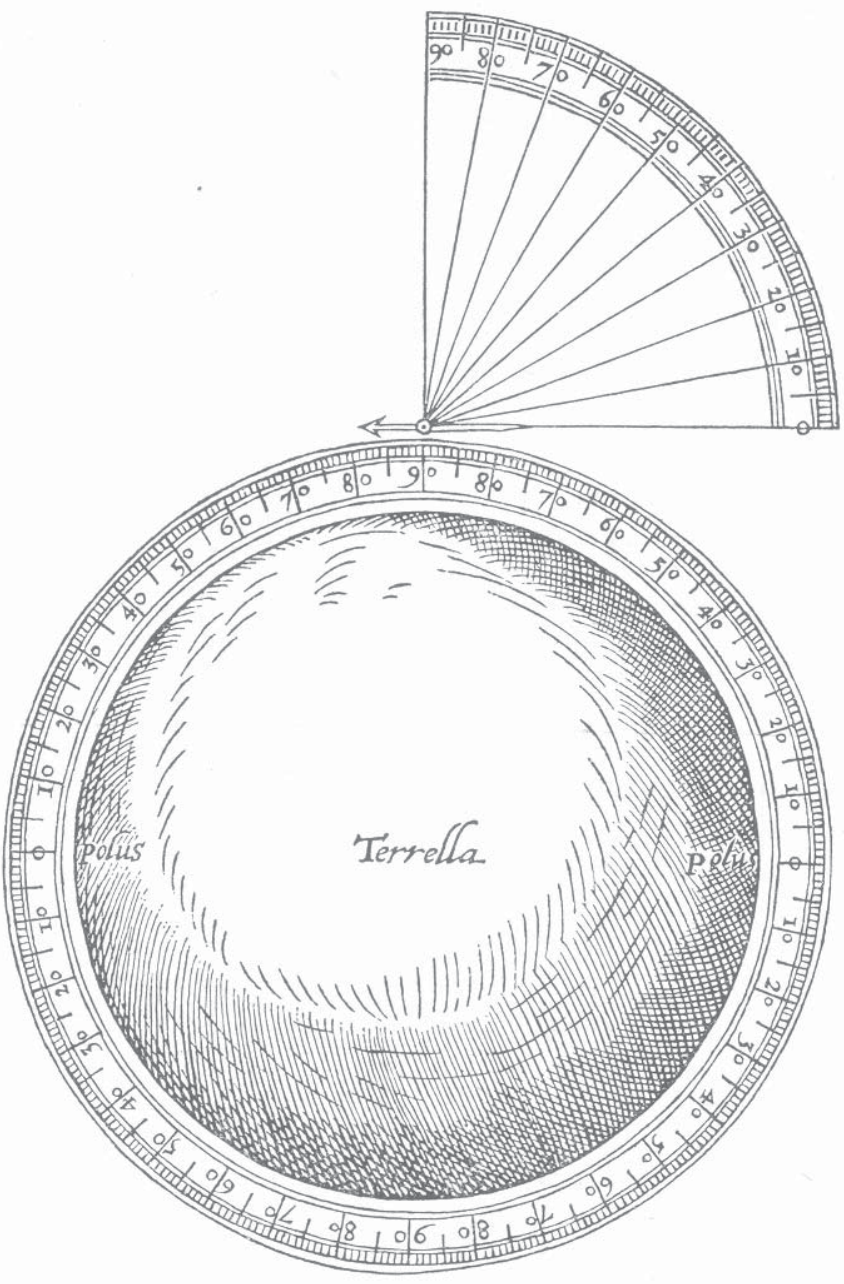
(desvio do meridiano) foi explicada pelas irregularidades da superfície da Terra (montanhas e mares) (IV, 2). Salientou que a inclinação da agulha magnética reflete a latitude (ver fig. 9).

O magnetismo, segundo Gilbert, seria a chave para a compreensão da natureza: uma forma não-corpórea, a "alma da Terra", agindo por união e concordância, ao passo que a eletricidade seria material, agindo por força e coesão através de eflúvios invisíveis (II, 2). Sua concepção magnética da Terra, que sentiria o magnetismo do Sol, teria grande influência sobre Johannes Kepler.

Figura 9. Montagem experimental para medir a inclinação ao longo de um meridiano da terrella, usada como modelo da Terra. A terrella é girada e o "versório" (agulha imantada) deixa de apontar na direção tangente à esfera, em um ângulo marcado no esquadro de madeira (Gilbert, $195^{8}$ [1600], p. 286). 


\title{
ComentáRIos Finais
}

O modelo causal esboçado para a ciência nascente do magnetismo mostra algumas diferenças em relação ao modelo causal da ciência madura no século xIx (visto, por exemplo, em Pessoa Júnior, 2000). As conexões causais na ciência nascente são mais simples do que na intrincada ciência madura. Nesta última, é mais comum haver três ou mais avanços que conjuntamente condicionam um novo avanço (ou seja, somente a conjunção de várias causas é suficiente para gerar o efeito), ao passo que na ciência nascente a tendência é um avanço gerar outro ou, no máximo, duas causas condicionarem um novo avanço. Outra característica da ciência nascente é a maior importância que têm manifestações culturais, como a adivinhação e a geomancia. Tanto é assim que a magia é considerada inseparável da ciência experimental nascente (cf. Thorndike, 1958-60).

Neste trabalho, introduzimos a noção de "avanço generalizado", exemplificado pela bússola de precisão, que engloba várias espécies diferentes de avanços semelhantes. Tais avanços generalizados desempenham papel importante na postulação de histórias possíveis, pois capturam o que há de essencial em um gargalo pelo qual passam diferentes histórias possíveis, abstraindo as diferenças acidentais.

\author{
Osvaldo Pessoa Júnior \\ Professor Doutor do Departamento de Filosofia, \\ Faculdade de Filosofia, Letras e Ciências Humanas, \\ Universidade de São Paulo, Brasil. \\ opessoa@usp.br
}

\begin{abstract}
This article presents a brief history of the beginning of the science of magnetism, which took place independently in three different continents. The methodology of causal models in the history of science is applied to represent these independent paths, where the notion of "developmental bottleneck" appears. Special attention is given to the definition of "generalized advances", which encompass different species of advances and simplify the causal diagrams. The historical survey covers the advances in magnetism in China and Europe until 1600.
\end{abstract}

KEYWords $\bullet$ Lodestone. Magnetic compass. History of magnetism. Causal models.

Developmental bottleneck. Generalized advances. 


\section{REFERÊNGIAS BIBLIOGRÁFICAS}

Aczes, A. D. Bússola: a invenção que mudou o mundo. Rio de Janeiro: Jorge Zahar, 2002.

Carlson, J. B. Lodestone compass: Chinese or Olmec primacy? Science, 189, 4205, p. 753-60, 5 set. 1975.

Daujat, J. Origines et formation de la théorie des phénomènes électriques et magnétiques. Paris: Hermann, $1945.3 \mathrm{v}$.

Gilbert, W. On the loadstone and magnetic bodies. New York: Dover, 1958 [1600].

Gillispie, C. C. (Org.). Dicionário de biografias científicas. Rio de Janeiro: Contraponto, 2007.

Grant, E. Peter Peregrinus. In: Gillispie, C. C. (Org.). Dicionário de biografias científicas. Rio de Janeiro: Contraponto, 2007. p. 2236-43.

Harradon, H. D. Some early contributions to the history of geomagnetism - I. Terrestrial Magnetism and Atmospheric Electricity, 48, p. 3-17, 1943a.

. Some early contributions to the history of geomagnetism - IV. Terrestrial Magnetism and Atmospheric Electricity, 4, 8, p. 127-3o, 1943b.

. Some early contributions to the history of geomagnetism -VII. Terrestrial Magnetism and Atmospheric Electricity, 49, p. 185-98, 1944.

KLокоÈníк, J. et al. F. Pyramids and ceremonial centers in Mesoamerica: were they oriented using a magnetic compass? Studia Geophysica et Geodaetica, 51, p. 515-33, 2007.

Lucrécio CAro, T. Da natureza. Os pensadores. São Paulo: Abril Cultural, p. 21-135, 1980 [c. 60 a.G.].

Malmström, V. H. Cycles of the sun, mysteries of the moon. Austin: University of Texas Press, 1997.

Mitchell, A. C. Chapters in the history of terrestrial magnetism. I: on the directive property of a magnet in the earth's field and the origin of the nautical compass. Terrestrial Magnetism and Atmospheric Electricity, 37 , p. 105-46, 1932 .

. Chapters in the history of terrestrial magnetism. II: the discovery of the magnetic declination. Terrestrial Magnetism and Atmospheric Electricity, 42, p. 241-80, 1937 .

. Chapters in the history of terrestrial magnetism. III: the discovery of the magnetic inclination. Terrestrial Magnetism and Atmospheric Electricity, 44, p. 77-80, 1939.

. Chapters in the history of terrestrial magnetism. IV: the development of magnetic science in classical antiquity. Terrestrial Magnetism and Atmospheric Electricity, 51, p. 323-51, 1946.

Needham, J. Science and civilization in China. Cambridge: Cambridge University Press, 1954. v. 1. . Science and civilization in China. Cambridge: Cambridge University Press, 1962. v. 4.

Peregrinus, P. The letter of Peter Peregrinus de Maricourt to Sygerus de Foucaucourt, soldier, concerning the magnet. Terrestrial Magnetism and Atmospheric Electricity, 4,8, p. 6-17, 1943 [1269].

Pessoa JúnIor, O. Histórias contrafactuais: o surgimento da física quântica. Estudos Avançados, 14, 39, p. $175^{-204,}, 2000$.

. Computation of probabilities in causal models of history of science. Principia, 10, p. 109-24, 2006. . The causal strength of scientific advances. In: Videira, A. A.P. \& Krause, D. (Org.). Brazilian studies in the history and philosophy of science. New York: Springer, No prelo. (Boston Studies in the Philosophy of Science).

TновNDike, L. A history of magic and experimental science during the first thirteen centuries of our era. New York: Columbia University Press, 1958-60. $8 \mathrm{v}$.

Videira, A. A.P. \& Krause, D. (Orgs.). Brazilian studies in the history and philosophy of science. New York: Springer, No prelo. (Boston Studies in the Philosophy of Science).

WASILEWSKi, P. \& KLeTETSGh KA, G. Lodestone: nature's only permanent magnet - what it is and how it gets charged. Geophysical Research Letters, 26, 15, p. 2275-78, 1999. 